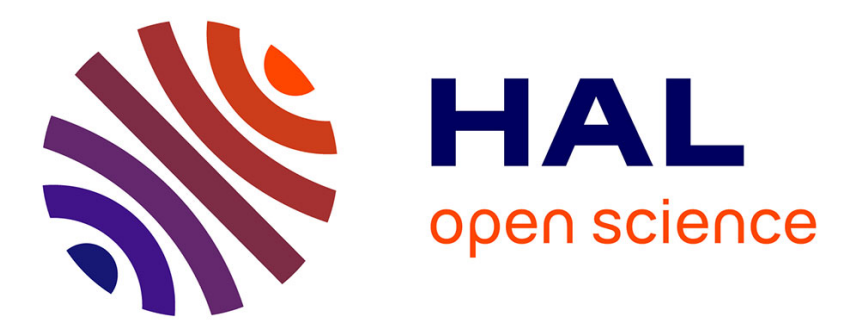

\title{
Application of very small angle neutron scattering to some problems of material science and nondestructive testing
}

K. Podurets, S. Shilstein, V. Somenkov

\section{> To cite this version:}

K. Podurets, S. Shilstein, V. Somenkov. Application of very small angle neutron scattering to some problems of material science and nondestructive testing. Journal de Physique IV Proceedings, 1993, 03 (C8), pp.C8-455-C8-458. 10.1051/jp4:1993894 • jpa-00252325

\section{HAL Id: jpa-00252325 \\ https://hal.science/jpa-00252325}

Submitted on 1 Jan 1993

HAL is a multi-disciplinary open access archive for the deposit and dissemination of scientific research documents, whether they are published or not. The documents may come from teaching and research institutions in France or abroad, or from public or private research centers.
L'archive ouverte pluridisciplinaire HAL, est destinée au dépôt et à la diffusion de documents scientifiques de niveau recherche, publiés ou non, émanant des établissements d'enseignement et de recherche français ou étrangers, des laboratoires publics ou privés. 


\title{
Application of very small angle neutron scattering to some problems of material science and nondestructive testing
}

\author{
K.M. PODURETS, S.S. SHILSTEIN and V.A. SOMENKOV
}

RSC “Kurchatov Institute”, Kurchatov sq., 123182 Moscow, Russia

\begin{abstract}
In neutron radiography some object details or domains of different composition that cause low variation of attenuation can be invisible. In the same time the macroscopic inhomogeneity domains $\left(-10^{-4} \mathrm{~cm}\right.$ scale) could be visible using VSANS technique. The big sensitivity of this method is due to the large VSANS cross section under the conditions of high angular resolution (about 1 sec of arc). Detection of the second phase precipitates and corrosion products on aluminium alloy are the examples of the method advantages. The second phase could be revealed at the level of $10^{-2}-10^{-3}$ volume fraction. The corrosion product layer of $10^{-4} \mathrm{~cm}$ thickness could be observed. VSANS could be used as sensitive method of nondestructive testing.
\end{abstract}

Precipitation of the second phase causes the durability loss of the materials and products. For instance, the presence of macro inclusions in the defendant details of the engine or hidden corrosion in the honeycomb panels could be the reason for heavy accidents of the aircraft. Problem of detection of macro inclusions can be solved by using the method of very small angle neutron scattering (VSANS) with the second of arc angular resolution. Aim of the present paper is to determine the sensitivity of VSANS for the detection of macro inclusions or their aggregations in the materials using for example the corrosion products and second phase precipitates in aluminium alloy.

Angular deviation of neutrons as a result of diffraction at the sphere of radius $r$ is defined by the equation [1]

$$
\Delta \phi=3^{1 / 2} \lambda /(2 \pi r)
$$

where $\lambda$ is the wavelength. So for the detection of big inclusions $\left(r>10^{-4} \mathrm{~cm}\right)$ the required angular resolution is of the order of angular second $\left(12\right.$ for $r=1 \cdot 10^{-4} \mathrm{~cm}$ and $\lambda=2.3 \AA$ ), which is characteristic for VSANS $[2,3]$.

Cross section of diffraction at the spherical inclusion amounts to [1]

$$
\sigma_{d i}=2 \pi r^{4} \lambda^{2}\left(N_{i} b_{i}-N_{m} b_{m}\right)^{2}
$$

where the values of scattering amplitude density $(\mathrm{Nb})_{i, m}$ correspond to the material of inclusion and metal respectively. Small angle scattering is usually considered as a weak process, but it is not so for macro inclusions. The reason is that the diffraction cross section grows according to the law $\sigma_{d i} r^{4}$, but the attenuation cross section grows as the volume of particle, $\sigma_{a^{-r}}$. So the ratio $\sigma_{d i} / \sigma_{a} \sim r$ grows as particle size. For $\mathrm{Al}_{2} \mathrm{O}_{3}\left(\mathrm{Nb}=5.86 \cdot 10^{10} \mathrm{~cm}^{-2}\right)$ sphere the diffraction cross section for thermal neutrons is close to the attenuation cross section $\sigma_{a=}(4 / 3) \pi r^{3} N\left(2 \sigma^{\mathrm{Al}} a+3 \sigma^{\mathrm{O}} a\right)$ for small precipitates, and for big ones $\left(r \sim 10^{-4} \mathrm{~cm}\right)$ the ratio $\sigma_{d i} / \sigma_{a}$ amounts to 300 (fig.1). So the small angle scattering at macro inclusions should be a strong process.

Diffraction attenuation of the beam after the pass $t$ in the metal with volume fraction of precipitate $\xi$ with uniform distribution is defined by the number of particles in unit volume $n_{i}=\xi /\left(4 \pi r^{3} / 3\right)$ :

$$
T_{d i}=\exp \left(-n_{i} \sigma_{d i} t\right)=\exp \left[-(3 / 2) \xi r \lambda^{2}\left(N_{i} b_{i}-N_{m} b_{m}\right)^{2} t\right]
$$


Let's estimate the effect of small angle diffraction for $\mathrm{Al}_{2} \mathrm{O}_{3}$ and $\mathrm{CuAl}_{2}$ precipitates in $\mathrm{Al}\left(N_{m} b_{m}=2.1 \cdot 10^{10} \mathrm{~cm}^{-2}, N_{i} b_{i}=3.16 \cdot 10^{10} \mathrm{~cm}^{-2}\right)$ for $t=1 \mathrm{~cm}$ for thermal and cold neutrons. Usual attenuation doesn't exceed the limit of contrast sensitivity of neutron radiography $(2-3 \%)$ for $\xi=10^{-2}$. So the domains of precipitation could not be revealed by both neutron radiography and transmission measurement without high angular resolution. Estimation of the diffraction attenuation according to (3) shows that the VSANS sensitivity to the volume part of precipitate amounts to $10^{-3}$. $10^{-2}$ for thermal neutrons and $10^{-4}-10^{-3}$ for cold neutrons (fig.2).

For not compact layer of the corrosion products the diffraction attenuation is defined by the cross section of single particle

$$
\sigma_{a}=2 \pi r^{4} \lambda^{2}\left(N_{p} b_{p}\right)^{2}
$$

where subscript $p$ corresponds to the corrosion product and the relative density $\eta$ :

$$
T_{a p}=\exp \left[-(3 / 2) \eta r \lambda^{2}\left(N_{p} b p\right)^{2}\right]
$$

Estimation of the beam attenuation according to (5) for the possible corrosion products $\mathrm{Al}(\mathrm{OH})_{3}$ and $\mathrm{AlO}(\mathrm{OH})$ as a function of the layer thickness with $r=1 \cdot 10^{-4} \mathrm{~cm}$ and usual atlenuation shows that the use of VSANS increases the sensitivity for the layer thickness by 1.2 orders of magnitude (fig. 3 ). In the case of $\mathrm{AlO}(\mathrm{OH})$ VSANS must reveal the monolayer of micron particles at the surface.

Experiment was carried out by using the double crystal spectromeler setup (fig.4a) at the STOIK spectrometer [4] in RSC KI. Angular resolution was about 1" for $\lambda=2.3 \mathrm{~A}$ and the width (FWHM) of the reflection curve $5 "$ (fig.4b). The sample was the duralumin plate $\left(150 \times 40 \times 1.4 \mathrm{~mm}^{3}\right)$ after the corrosion treatment, after which a half of the plate had been covered with a thin corrosion layer. Variation of the beam path length inside the sample was done by inclination of sample at the small angle $\alpha$ to the beam (in this case $t_{\text {eff }}=t /(\sin \alpha)$ ). Scattering curves (fig. $4 \mathrm{c}, \mathrm{d}$ ) and the curve of scanning the sample by narrow beam ( $3 \mathrm{~mm}$ width) at the peak position of scattering curves (fig.4e) were taken. The image of the corrosion spot was obtained by the X-ray film with Gd converter placed in front of the detector (fig.4f).

A narrow peak of the same width as for the reflection curve without a sample could be observed at the scattering curve for the initial alloy (fig.4c), which is applied to the more wide peak with the width of about $20^{\prime \prime}$ and nearly the same area. It means that half of neutrons is scattered to the angle of $10^{\prime \prime}$ and others are not diffracted, so $T_{d}=0.5$. This leads to the precipitate size of $1.3 \cdot 10^{-4} \mathrm{~cm}$. Assuming that small angle scattering in the duralumin is due to the intermetallide precipitate $\mathrm{CuAl}_{2}$, the volume part of it amounts to $\xi=0.09$. In the case of presence of oxide precipitate their total fraction is less and equals to several percent. Experimental data shows that the effect of small angle scattering could be observed for $\xi<10^{-2}$, in accordance with the results of study of the hydride precipitation in $\mathrm{Nb}$ [5].

For the corroded part of the sample the diffraction attenuation in the corrosion layer and in alloy itself are approximately equal (fig.4c), and the shape of the curve is close to that of the sample without corrosion. It means that the size of corrosion product particles is close to $1 \cdot 10^{-4} \mathrm{~cm}$. Thickness of the layer was measured as $(7-10) \cdot 10^{-4} \mathrm{~cm}$ from usual attenuation. The expected diffraction attenuation for this thickness is less than $5 \%$ for $\mathrm{Al}(\mathrm{OH})_{3}$ and nearly $40 \%$ for $\mathrm{AlO}(\mathrm{OH})$ according to (5). So we can decide that the composition of layer is close to $\mathrm{AlO}(\mathrm{OH})$. As the diffraction attenuation in this layer is much bigger than the minimal measurable 
value we can expect that the minimal detectable layer approaches $10^{-4} \mathrm{~cm}$ in accordance to estimation results (fig.2).

Radiograph of the corrosion spot taken at $\alpha=10^{\circ}$ shows its irregular shape and thickness by variations of contrast (fig.4f). Zones of inhomogeneous density of precipitate and voids can be also visualized [8].

Results of this work as well as [6,7] confirm in principle the possibility of detection of precipitates and corrosion products in alloys by means of VSANS. Real perspective of the VSANS based method of nondestructive testing is not obvious and is defined by several factors, such as the use of reactor and transportation expenses. The most simple task could be the control of a product as a whole by gauging the attenuation and determination of average density of precipitate or corrosion layer thickness. It can be solved not only using the double perfect crystal setup but also using highly collimated cold neutron beams available at neutron guides.

The work is supported by the Russian Foundation for the Basic Research.

\section{References}

1. Bacon G.E., Neutron Diffraction, 3rd ed., Oxford, Clarendon Press, 1975.

2. Shull C.G., Schneider C.S., Phys.Rev. B3 (1971) 830.

3. Shilstein S.S. et al, Pribory i Tekhnika Eksperimenta, 1971, 3, 70 (in Russiau).

4. Naumov I.V. et al, ibid, $1988,5,42$.

5. Kalanov. M. et al, Sov.Phys.Cryst., 18 (1974) 755.

6. Podurets K.M. et al, Proceddings of the 4 th World Conference on Neutron Radiography, to be published.

7. Kvardakov V.V. et al, ibid.

8. Shilstein S.Sh., Proc. of the International Scool of Physics "Enrico Fermi", ed. M.Fontana and F.Rustichelli, North Holland, 1992, p.457.

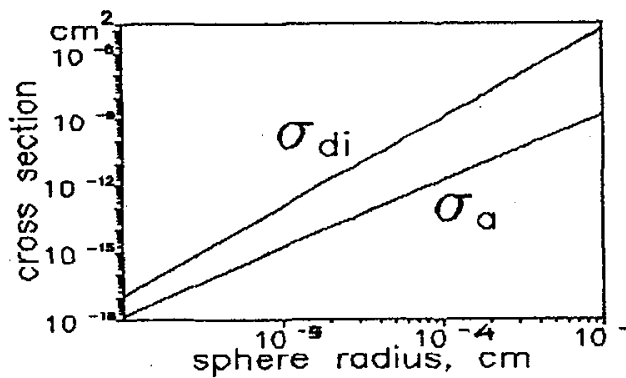

Fig.1. Cross sections of diffraction $\left(\sigma_{d i}\right)$ and attenuation $\left(\sigma_{a}\right)$ for $\mathrm{Al}_{2} \mathrm{O}_{3}$ particles in $\mathrm{Al}$ matrix $\left(r=1 \cdot 10^{-4} \mathrm{~cm}\right)$.

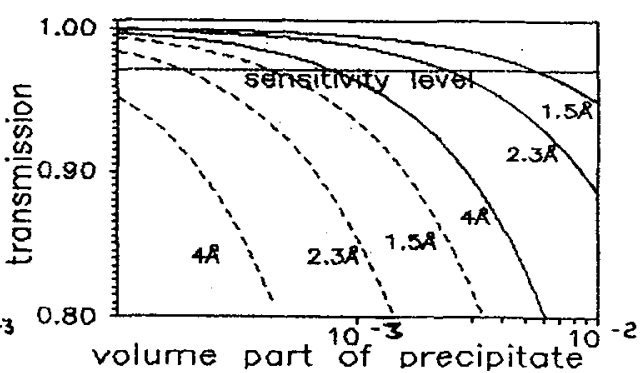

Fig.2. Estimated transmission for $1 \mathrm{~cm}$ sample of $\mathrm{Al}$ with the inclusions of $\mathrm{Al}_{2} \mathrm{O}_{3}$ due to attenuation (solid) and diffraction (dashed line). 

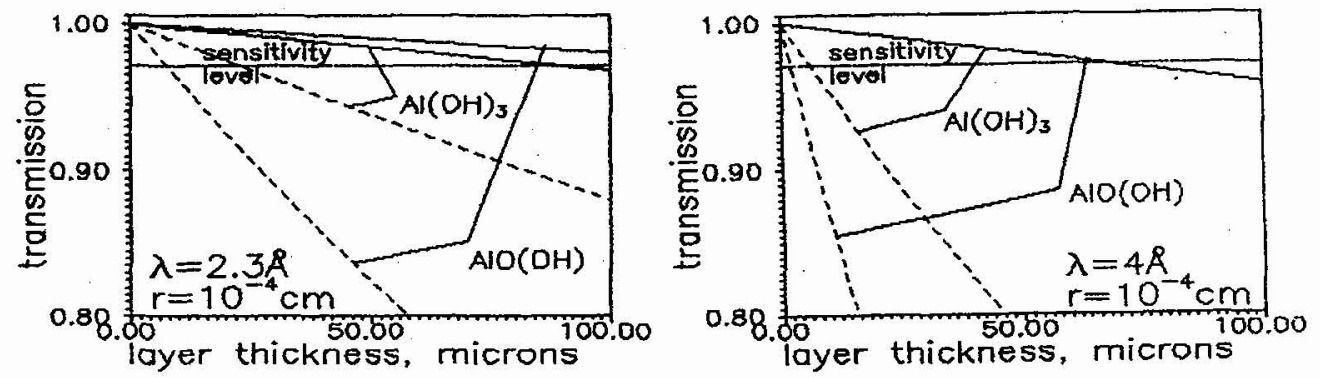

Fig.3. Estimated transmission for the corrosion layer on Al due to attenuation (solid) and diffraction (dashed line) for different wavelengths.
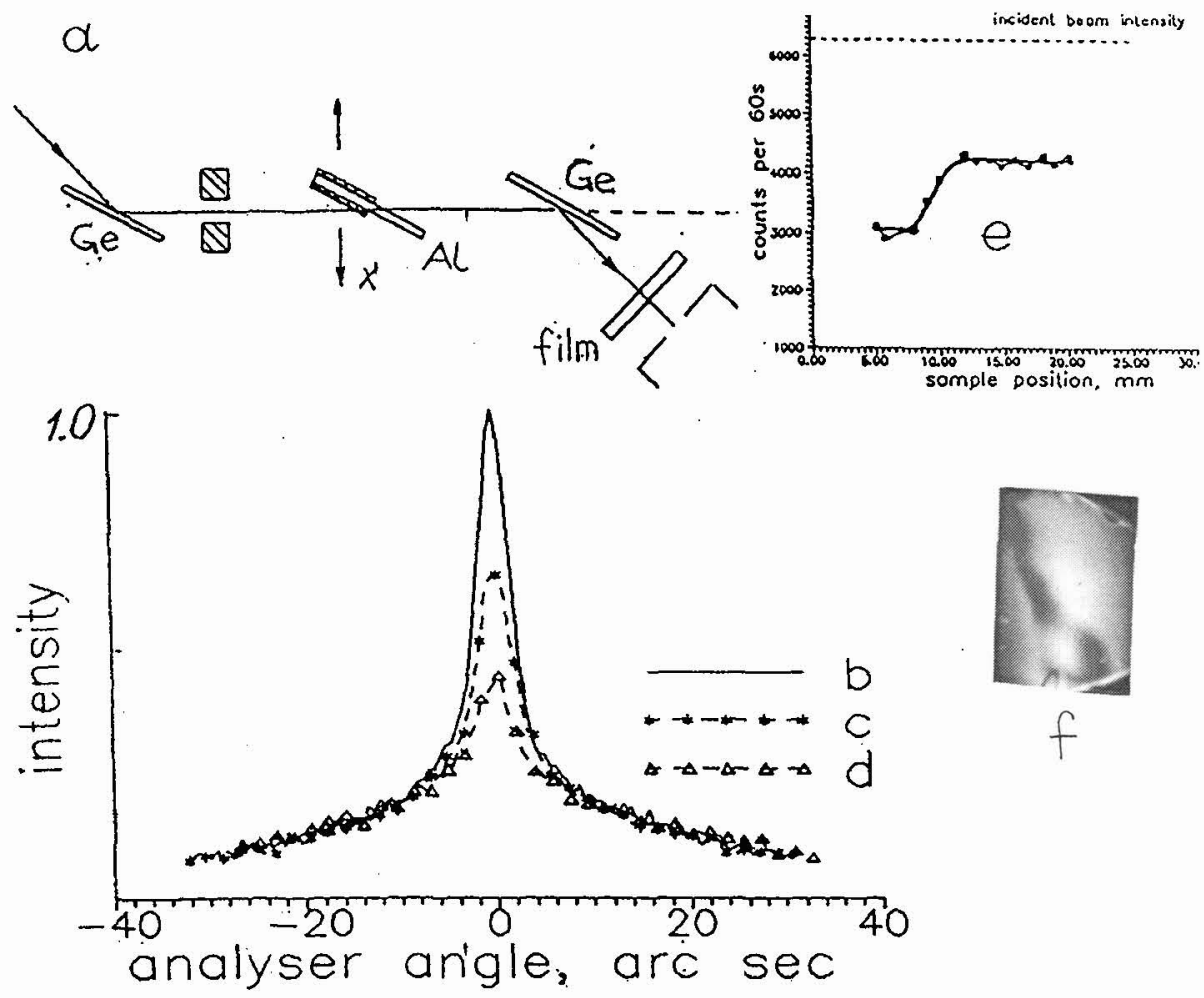

Fig.4. Detection of the corrrosion layer on Al: experimental setup (a), initial reflection curve (b), scattering curves for the sample without corrosionlayer (c) and with it (d), scanning curve obtained by translation of sample against the $3 \mathrm{~mm}$ slit (e), radiograph of the sample (f). 